\title{
Empathy, personality traits, and emotional management in 2nd and 4th-year dentistry students: a single-center study
}

\author{
Christian Lermen ${ }^{1}$, Willi Wetzel ${ }^{2}$, Vanessa Britz ${ }^{3}$, Jasmina Sterz ${ }^{4}$, Wolf O Bechstein ${ }^{1}$ and Teresa Schreckenbach ${ }^{{ }^{*}}$
}

\begin{abstract}
Background: Patients fearing dental interventions are at risk of delaying or skipping much-needed treatments. Empathic communication could lead to a higher rate of compliance from patients within this group. Empathy, the big five personality traits, and emotion management abilities are all known to influence the quality of communication between dentists and patients. This study was conducted to analyze whether there is a correlation between these factors in dentistry students.

Methods: Dentistry students in their 2 nd and 4 th year of study were asked to complete questionnaires assessing empathy, emotion management, and personality traits. Out of a total of 148 eligible participants, 53 students (34\%) volunteered to participate. For empathy, the Jefferson Scale of Physician Empathy (students'version; JSPE-S) and the Interpersonal Reactivity Index (IRI) were used. Personality traits were assessed using the Short Big Five Inventory (BFIs), and the Situational Test of Emotional Management (STEM) to measure emotional management ability.
\end{abstract}

Results: Higher scores for emotion management were significantly correlated with the female gender $(p \leq 0.005)$ and with higher scores in openness $(p \leq 0.05)$. Students with higher scores in openness also achieved higher scores on the IRI subscales: Perspective taking ( $p \leq 0.05)$, Fantasy $(p \leq 0.01)$, Empathic concern ( $p \leq 0.05)$, and Personal distress $(p \leq 0.05)$. For JSPE-S, no correlation with emotion management and personality traits was found.

Conclusion: Empathy and emotion management might not be significantly related in dentistry students. Regarding personality traits, students who scored higher on openness also indicated higher abilities in emotion management. These findings should be taken into consideration when planning communication courses for dentistry students, as it might be possible to independently train empathy and emotion management as part of emotional intelligence.

Keywords: Empathy, Personality inventory, Emotional intelligence, Dental students

\section{Introduction}

Face-to-face communication should not be underestimated as part of the doctor-patient relationship [1]. Especially in situations that are associated with fear for a

*Correspondence: Teresa.Schreckenbach@kgu.de

${ }^{1}$ Goethe-University Frankfurt/Main, Department of General, Visceral, Transplantation and Thoracic Surgery, Goethe-University Frankfurt am Main, Frankfurt University Hospital and Clinics, Theodor-Stern-Kai 7, 60596 Frankfurt/Main, Germany

Full list of author information is available at the end of the article greater number of patients, communication can make the difference [1,2]. Around $60 \%$ of patients in Germany fear dental interventions [3]. Worldwide, between 6 and 21\% of dental patients report a severe fear of the dentist [3]. Patients with dental fear are more likely to delay necessary controls and treatments, which can result in the loss of teeth $[4,5]$. Patient-centered communication could prevent at least some of the delayed dental treatments [5].

Therefore, the realization that empathic communication makes a decisive contribution to therapy adherence 
and success is also evident in the new revision of the dental license regulations in Germany [6]. In this revision of the license to practice, which originally dates back to 1955, communication is set for the first time as a learning goal within the framework of dental/medical studies [6]. The recommendation results from the learning objectives of the German National Competence-Based Learning Objectives Catalog of Dentistry (NKLZ), which was introduced in 2015 [7]. The NKLZ describes the graduate profile of dentists from dental/medical school and should serve as an orientation for faculties and dentistry students. It relates to the CanMEDs rolls [8], and defines the dentist as a communicator who is capable of effective patient-centered communication [7].

Empathy is one part of effective patient-centered communication [1]. It is also part of the concept of Emotional Intelligence, which is needed for successful communication [9]. There are multiple models of emotional intelligence, for example, the ability and trait emotional intelligence and mixed models [10]. Most of them understand emotional intelligence as a combination of various components: (1) perceiving emotion (emotion recognition), (2) facilitating thought with emotion, (3) understanding emotion, and (4) managing emotion [11]. Managing emotions does not only mean managing the emotions of other people but also one's own emotions [9]. High scores on emotion management ability relates to successful communication and the achievement of personal and interpersonal goals [12]. Improving one's own strategies for emotion management could help to improve empathic communication in doctor-patient relationships [13]. This would be a possible aim for promotion in dentistry students.

For pro-social communications, it was shown that possessing high levels of emotional intelligence is not enough [14]. How emotional intelligence is used in interpersonal communication is dependent on certain personality traits [15]. For example, whether individuals use their emotion recognition ability for prosocial behavior depends strongly on their personality traits $[15,16]$. There are different theories for personality traits. One of the most often used and well-established theories is the Five-Factor model, also known as the Big Five Inventory, defining five broad dimensions of personality traits: (1) openness, (2) conscientiousness, (3) extraversion, (4) agreeableness, and (5) neuroticism [17].

This raises the question of whether there is a correlation between emotion management, personality traits and empathy. Collecting data for interrelationship areas of emotional intelligence is important to understand the complex interplay of individual emotional abilities. For creating effective teaching methods for patient-centered communication, it is important to understand this relationship. So far, no studies analyzing emotion management and its relationship with student's personality or empathy have been conducted with dentistry students.

This study attempted to answer the questions of whether 1) self-assessed empathy and emotion management abilities differ between 2nd and 4th year dentistry students, and 2) whether there is a correlation between empathy, personality traits, and emotion management abilities.

\section{Materials and methods Study protocol}

This study was conducted in accordance with the Helsinki Declaration (Ethical Principles for Medical Research Involving Human Subjects), and the study was performed with the permission of the Ethics Committee of the Goethe University, Frankfurt, Germany (IRB No. 19-225). All dental students enrolled in the second $(n=86)$ and fourth year $(n=62)$ at the University of Frankfurt/Main were asked to participate in this study. Participation in the study was voluntary and took place after written informed consent. The questionnaires were completed anonymously so that no conclusions could be drawn about the student involved.

\section{Self-assessment of empathy}

For empathy assessment two self-assessment questionnaires were used. The Jefferson Scale of Physician Empathy Students version (JSPE-S) and the Interpersonal Reactivity Index (IRI) are widely known and used, which offers an option for international comparison [18, 19]. Self-assessment was used to enable a better comparison of the assessed level of empathy between the students of the different academic years. Students in the 4th year of study have already gained experience with patients compared to those in the 2nd year, which could falsify a patient-centered empathy assessment, as it is used in the Consultation and Relational Empathy (CARE) Measure [20].

\section{Jefferson scale physician empathy students version (JSPE-S)}

The German version of the Jefferson Scale Physician Empathy Students Version (JSPE-S) was used to measure the students' subjectively perceived empathy relevance in medicine [21]. The JSPE-S is a 20-item-questionnaire [18]. Respondents indicate their level of agreement on a 7-point Likert scale [1 (strongly disagree)-7 (strongly agree)]. The test assesses the participants' level of empathy based on three subcategories: Perspective Taking (range, 10 to 70 points), Compassionate Care (range, 8 to 56 points), and walking in patients' shoes (range, 2 to 14 points) [18]. 


\section{Interpersonal reactivity index (IRI)}

The German version of the Interpersonal Reactivity Index (IRI) as a self-report, comprising 28 -items answered on a 5-point Likert scale, was used to conduct a multidimensional assessment of empathy [22]. It is divided into four subscales: 1. Perspective Taking, 2. Fantasy, 3. Empathic Concern, and 4. Personal Distress [19]. Each participant can receive between 0 to 28 points on each subscale.

\section{Personality traits - BIG-five-inventory short version (BFI-K)}

Personality traits were determined using the German version of the Big Five Inventory short version (BFIK) questionnaire, which was established in 2005 as a short version of the BFI [23]. The items were rated on a 5 -point Likert scale ranging from $1=$ strongly disagree.

to $5=$ strongly agree. It consists of 21 items assessing participants level of extraversion (range, 4 to 20 points), openness to experience (range, 5 to 25 points), conscientiousness (range, 4 to 20 points), agreeableness (range, 4 to 20 points), and neuroticism (range, 4 to 20 points) [23].

\section{Situational test of emotional management (STEM)}

Emotion management abilities were measured using the Situational Test of Emotion Management (STEM) [24]. This consists of 44 multiple-choice items. Each item consists of a description of an emotional situation as well as four possible reactions [24]. The participants had to decide which reaction would be the most suitable. There are no correct answers in the conventional sense. However, answers were ranked by experts according to suitability. Students received one point for choosing the answer most preferred by experts.

\section{Statistics}

All statistical analyses were performed using International Business Machines Corporation (IBM) Statistical Package for the Social Sciences (SPSS) for Windows (version 25.0; IBM, Chicago, IL, USA). Cronbach's alpha was used to evaluate the reliability of the questionnaires. For analyzing the difference between the students, MannWhitney $U$ test as non-parametric test for not equally distributed parameters was used. The associations between emotional management, empathy, and each personality trait were assessed using Pearson's Correlation Coefficient. All correlations were two-tailed, and a $p$-value $<0.05$ was considered statistically significant.

\section{Results}

\section{Participants}

Out of the total of 148 eligible participants, 53 students (34\%) volunteered to participate. Thirty questionnaires were received from the second-year students and 23 from the fourth-year students. Thirty-four students were female, and 16 were male. The median age was 24 years (SD, 3.8), with a range from 19 to 32 years.

Of all students, 33 (62.3\%) had no previous vocational training before enrollment at dental/medical school. There were no differences between the second- and fourth-year students for scores in JSPE-S, IRI, BFI-K, and STEM (Table 1).

\section{Descriptive analysis of JSPE-S, BFI-K, and STEM}

For the JSPE-S subscales, the following mean scores were achieved: Perspective Taking, 55.6 (SD 7.5); Compassionate Care, 42.0 (SD 6.6); Walking in Patients' Shoes, 8.6 (SD 2.7). Cronbach's Alpha for the subscales were: "Perspective Taking": 0.7; "Compassionate Care": 0.6; "Walking in Patients' Shoes”: 0.7.

For IRI subscales, the students showed the following mean scores: Perspective Taking, 18.7 (SD, 3.9), Fantasy, 18.0 (SD, 5.8), Empathic Concern, 20.7 (SD, 4.4), and Personal Distress, 9.1 (SD, 4.4). Cronbach's Alpha for the subscales were: "Perspective Taking": 0.7; "Fantasy": 0.8; "Empathic Concern": 0.8; and "Personal distress": 0.7.

The results of the BFI-K were: Agreeableness, 12.2 (SD, 3.2), Extraversion, 15.2 (SD 3.3), Openness, 20.9 (SD, 2.9), Conscientiousness, 15.7 (SD, 2.5), and Neuroticism, 11.4 (SD, 3.6). Internal consistency of extraversion (four items) was $\alpha=0.8$, openness $\alpha=0.6$, agreeableness $\alpha=0.7$; conscientiousness $\alpha=0.6$; and neuroticism $\alpha=0.8$.

For STEM, the students reached a mean score of 31.9 (SD, 4.8). Weighted to the expert results, students achieved $72.4 \%$ of the possible best answers. Internal consistency for STEM was $\alpha=0.7$.

\section{Correlation between self-assessed empathy, personality traits, and emotional management abilities}

Students scoring high in openness in BFI-K achieved statistically significantly higher scores on all IRI subscales: Perspective Taking $(p \leq 0.05)$, Fantasy $(p \leq 0.01)$, Empathic Concern $(\mathrm{p} \leq 0.05)$, and Personal Distress $(\mathrm{p} \leq 0.05)$. Students who scored highly in agreeableness achieved significantly higher scores on the Empathic Concern scale $(\mathrm{p} \leq 0.05)$ and the Personal distress scale $(p<0.05)$. A conscientious personality was associated with significantly lower scores on the IRI subscales Empathic concern $(\mathrm{p} \leq 0.05)$ and Personal distress $(\mathrm{p} \leq 0.05)$. Neuroticism showed a significant correlation with IRI subscales Fantasy ( $\mathrm{p} \leq 0.05)$, Empathic concern $(\mathrm{p} \leq 0.01)$, and Personal distress $(p=0.01)$.

High scores on the STEM questionnaire were significantly correlated with female gender $(\mathrm{p}<0.05)$, higher 
Table 1 Demographic data of participants and descriptive analyses of JSPE-S, IRI, BFI-K, and STEM

\begin{tabular}{|c|c|c|c|}
\hline & $\begin{array}{l}\text { Students } 2 \text { nd year } \\
\mathrm{N}(\%)\end{array}$ & $\begin{array}{l}\text { Students 4th year } \\
\mathrm{N}(\%)\end{array}$ & P-Value \\
\hline Gender & & & 0.973 \\
\hline female & $21(70.0)$ & $16(69.6)$ & \\
\hline male & $9(30.0)$ & $7(30.4)$ & \\
\hline $\begin{array}{l}\text { Vocational Training (before enrollment at dentistryl } \\
\text { school) }\end{array}$ & & & 0.161 \\
\hline nurse & $0(0.0)$ & $1(4.3)$ & \\
\hline dental assistant & $1(3.3)$ & $0(0.0)$ & \\
\hline dental technician & $3(10.0)$ & $3(13.0)$ & \\
\hline \multirow[t]{2}{*}{ others } & $10(33.3)$ & $2(8.7)$ & \\
\hline & $\begin{array}{l}\text { Students 2nd year } \\
\text { Mean (SD) }\end{array}$ & $\begin{array}{l}\text { Students 4th year } \\
\text { Mean (SD) }\end{array}$ & P-Value \\
\hline Age (in years) & $23.8(4.5)$ & $23.8(2.7)$ & 0.995 \\
\hline \multicolumn{4}{|l|}{ JSPE-S } \\
\hline Perspective Taking & $54.9(8.02)$ & $56.6(6.7)$ & 0.425 \\
\hline Compassionate Care & $41.4(7.3)$ & $42.7(5.5)$ & 0.492 \\
\hline Walking in Patients'Shoes & $9.10(2.8)$ & $7.8(2.5)$ & 0.092 \\
\hline \multicolumn{4}{|l|}{$|\mathrm{R}|$} \\
\hline Perspective Taking & $19.2(4.2)$ & $18.0(3.4)$ & 0.306 \\
\hline Fantasy Scale & $18.2(6.2)$ & $17.8(5.4)$ & 0.835 \\
\hline Empathic concern scale & $21.6(4.0)$ & $19.4(4.8)$ & 0.073 \\
\hline Personal distress Scale & $9.2(4.5)$ & $9.0(4.4)$ & 0.921 \\
\hline \multicolumn{4}{|l|}{ BFI-K } \\
\hline Agreeableness & $12.0(3.3)$ & $12.4(3.0)$ & 0.597 \\
\hline Extraversion & $15.9(3.5)$ & $14.3(2.9)$ & 0.079 \\
\hline Openness & $20.7(3.1)$ & $21.1(2.8)$ & 0.636 \\
\hline Conscientiousness & $15.2(2.8)$ & $16.2(2.1)$ & 0.165 \\
\hline Neuroticism & $11.7(3.7)$ & $10.9(3.3)$ & 0.429 \\
\hline STEM & $31.6(5.4)$ & $32.4(4.0)$ & 0.569 \\
\hline
\end{tabular}

scores on the IRI-Fantasy subscale $(\mathrm{p}<0.05)$, IRI-Personal distress scale $(p<0.001)$, and higher scores in openness $(\mathrm{p}<0.05)$. The complete results are shown in Table 2.

\section{Discussion}

Emotional intelligence and empathy are part of patientcentered communication and are known to differ between individuals, depending on personality traits, amongst other things $[25,26]$. For creating effective teaching methods for patient-centered communication, it is important to understand this relationship.

Thus, this study was conducted to analyze the correlation between self-assessed empathy, personality traits, and emotion management abilities as one part of emotional intelligence in dentistry students. This demonstrates that female students and students with a more open personality scored the highest for self-assessed empathy and showed the best emotion management abilities.
One of the most frequently examined factors influencing empathy and emotional intelligence is gender. Many studies have shown that women score higher in self-assessed empathic behavior and emotional intelligence [27-29]. One reason for this could be that women often express more emotions and have shown higher skills for effective interpersonal relationships and communication [18, 29]. However, some studies have suggested that this self-assessment could be falsified by socially prescribed role models [30]. Fisher et al. could show that men rated lower in self-reported emotional intelligence but showed the same perception for emotions as women [28]. These statements are supported by studies which have shown that when empathy was assessed by patients and simulated patients, gender had no influence [25]. Other authors suspect not necessarily a difference between men and women for global emotional intelligence but more for single facets of emotional intelligence $[29,31]$. Women were 


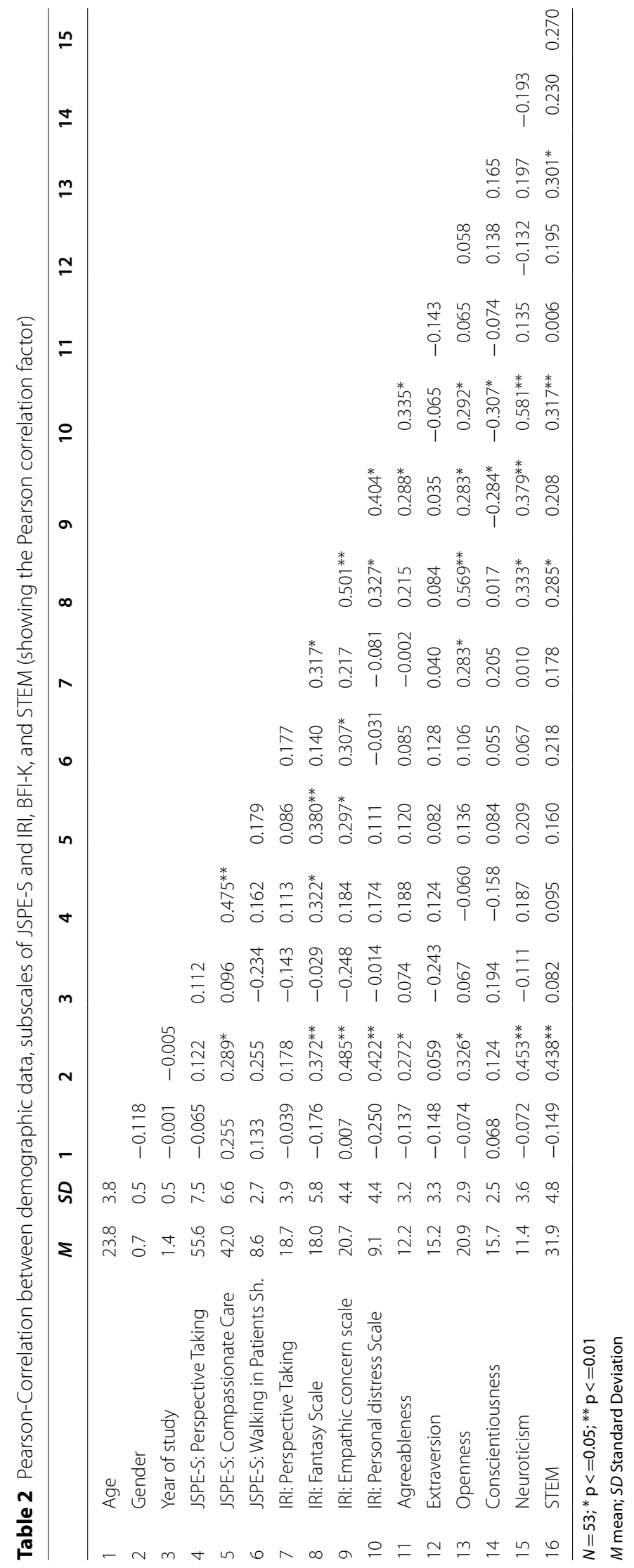


shown to score higher for impulse control and relationship, differing from men who showed better stress management [31].

These results can be further extended to the question of what influence has personality on empathy. Studies with self-assessed empathy skills showed individuals with a more agreeable and open personality rated higher for empathy than individuals with other personality traits [32, 33].

In addition to these personality types, emotional intelligence also counts as an influencing factor on empathy. Among other things, emotional intelligence includes the ability to understand emotions, emotional experience, and the ability to manage emotions [9].

The concept of the differences between two main areas of emotional intelligence, trait and ability emotional intelligence, was discussed in previous studies [10]. Emotional intelligence ability is seen as the part of emotional intelligence which can be taught [34]. This part of emotional intelligence could be relevant for the development of teaching concepts for patient-centered communication in dentistry students [35]. In contrast, trait emotional intelligence was shown to be part of individual personality and correlates with the five-factor model of personality [36], in contrast to emotional intelligence ability. The present study found a significant correlation of emotion management abilities as part of emotional intelligence with students' expression of openness as a personality trait but not with the other four personality traits equal with other studies [37, 38].

For measuring empathy different approaches are used. Some authors use self-assessment questionnaires, similar to this study [27, 33]. However, self-assessment questionnaires could lead to the problem of socially desirable answers [30]. Therefore, other authors had the empathic behavior of students assessed by patients, simulated patients, or teachers [25]. For external assessment the CARE questionnaire can be used. The CARE Scala consists of 10 items, which provide a quick and uncomplicated assessment of empathic behavior [20]. It was developed by Mercer et al. and can be applied to many medical professions [20]. Barbar et al. used the CARE Scale in their study with dentistry students [39]. Second year students achieved higher scores on the CARE Scale than fourth year students. The authors were also able to show a positive correlation between self-assessed empathy and the CARE scale [39].

The decline in empathy, which was shown in that study [39], is also known from medical students [26, 40]. Reasons for this could be an increase in professional behavior, as well as stress, workload, and psychological fatigue [41-43]. Psychological health and well-being of individuals also have an influence on emotion management abilities [24, 44]. Individuals suffering from anxiety and depression show lesser abilities of emotion management than individuals who are mentally healthy [24].

Many studies on empathy use one of the questionnaires mentioned above, which enables comparability between the studies. This reveals the cultural background of the students as another factor influencing empathy and emotional management $[25,45]$. Chatterjee at al. used the JSPE-S for Indian medical students and found a lower empathy level compared to studies from other countries [27]. The authors suspect a connection with a more paternalistic doctor-patient relationship model compared to other countries [27].

Since empathy and emotion management are important for a successful doctor-patient relationship, targeted training would be desirable. A 6-year longitudinal study by Kataoka et al. was able to show a positive influence of communication training on empathy of medical students [46]. Daryazadeh et al. used a narrative approach to train self-reflection and empathy and were able to show an increase in both after a session of only two hours [47]. Other studies with a wide variety of training approaches have also shown an improvement in the doctor/studentpatient relationship [48].

\section{Implication for further research and training}

A focus of further studies should be on creating courses for patient-centered communication, whose structures are based on the individual skills of the students. For example, students with low scores in emotion management could be taught in stress management abilities, while courses in communication could be offered for students with more introverted or neurotic personality traits.

The results of this study should also be checked in a larger cohort. Furthermore, the connection between empathy, emotional management and the cultural background of the students should be analyzed in more detail. It would be important to find out whether the family's cultural background or the cultural area of the place of study have an influence.

In order to find out more about the influence of personal distress, it would be helpful to take a closer look using a questionnaire with more detailed questions about personal distress than the IRI. Future research should also include global emotional intelligence measurement and analyses of students' psychological well-being and depression levels.

\section{Limitations}

This study has a few limitations. First, this investigation focused on students at two different points in dentistry training. Thus, this study might not reflect the 
performance of students in earlier or later years of dentistry school as it analyses students at the beginning and in the middle of their education to get an overlook about emotion management abilities during dentistry education.

Using self-assessment forms to estimate personality dimensions might have resulted in biased data. Studies have shown that individuals tend to answer in socially acceptable dimensions, which could lead to false data [30]. On the other hand, filling in the questionnaires might result in self-reflection on the part of the participants, which could lead to more self-confidence in communication with patients. For emotion management, only the ability, and not trait emotional intelligence or global emotional intelligence was measured, which only gives a limited view on emotional intelligence.

Only one-third of both student years completed the questionnaire, which resulted in a relatively small number of participants, causing a possible influence on the quantitative analyzes. A higher number of participants may have led to a different, and significant result.

Despite these limitations, this study also has some strengths. To our knowledge, this is the first study analyzing the correlation between empathy, personality traits, and emotion management abilities in dentistry students. The questionnaires used in this study are used internationally and have been evaluated in various studies, and the study design is transferable to other institutions.

\section{Conclusion}

The present study investigated the correlation between self-assessed empathy, personality traits and emotion management abilities in 2nd- and 4th-year dentistry students. No differences between the two years of study could be found. Higher emotional management abilities were correlated with the female gender and a more open personality. Emotional management ability correlated with the IRI subscales "Fantasy" and "Personal Distress". However, there was no correlation between any subscale of the JSPE or the other subscales of the IRI measuring self-assessed empathy. These findings should be kept in mind when planning communication courses for dentistry students. For example, empathy and emotion management as parts of emotional intelligence might be independently trainable.

\section{Abbreviations}

BFI-s: Short Big Five Inventory; IRI: Interpersonal Reactivity Index; JSPE-S: Jefferson Scale of Physician Empathy; NKLZ: German NationalCompetenceBased Learning Objectives Catalog of Dentistry; SD: Standard Deviation; STEM: Situational Test of Emotional Management.

\section{Acknowledgments}

The authors would like to thank Prof. Myriam Bechtoldt of the European Business School for years of help in understanding the complexity of empathy and related psychological traits and for profound advice on the analysis of the psychological questionnaire.

\section{Authors' contributions}

The study was designed by CL, WW, JS and TS. Participants were recruited by $\mathrm{CL}, \mathrm{WW}$ and VB. CL; WW, VB and JS transferred the data from the questionnaires to the database. CL, TS and WB performed the statistical analyzes and result interpretation. $C L, W W$ and TS drafted the article. WW, VB, JS, WB, and TS revised it critically for important intellectual content. All authors read and approved the final manuscript.

\section{Authors' information}

Christian Lermen is alicensed dentist, who is writing his doctoral thesis at Goethe-UniversityFrankfurt am Main, Frankfurt University Hospital and Clinics, Department ofGeneral, Visceral and Transplantation Surgery, Theodor-SternKai 7, 60596Frankfurt/Main, Germany.

Willi Wetzel is alicensed dentist, who is working at the Goethe-University Frankfurt am Main,Carolinum, Department of Oral Surgery and Implantology, Theodor-Stern-Kai 7,60596 Frankfurt/Main, Germany.

Dr. med. Vanessa Britzis a licensed physician, working at the Goethe-University Frankfurt am Main,Department of Trauma, Hand and Reconstructive Surgery, University HospitalFrankfurt, and for the Frankfurt interdisciplinary simulation center FIneST,medical faculty, Goethe University, Theodor-Stern-Kai 7, 60596 Frankfurt/Main,Germany.

Dr. med. JasminaSterz is a licensed physician working at the Goethe-University Frankfurt amMain, Department of Trauma, Hand and Reconstructive Surgery, UniversityHospital Frankfurt, and for the Frankfurt interdisciplinary simulation centerFIneST, medical faculty, Goethe University, Theodor-Stern-Kai 7, 60596Frankfurt/Main, Germany. She holds a Master degree for Medical Education.

Prof. Dr. med. WolfO. Bechstein is a licensed surgeon and head of the Department of General,Visceral and Transplantation Surgery, at Goethe-University Frankfurt am Main,Frankfurt University Hospital and Clinics, Theodor-Stern-Kai 7, 60596Frankfurt/Main, Germany.

Dr. med. TeresaSchreckenbach is senior physician of the Department of General, Visceral andTransplantation Surgery, at Goethe-University Frankfurt am Main, FrankfurtUniversity Hospital and Clinics, Theodor-Stern-Kai 7, 60596 Frankfurt/Main,Germany. She holds a Master degree for Medical Education.

Funding

Open Access funding enabled and organized by Projekt DEAL.

\section{Availability of data and materials}

The datasets used and analyzed during the current study are available from the corresponding author on reasonable request.

\section{Declarations}

\section{Ethics approval and consent to participate}

The study was conducted according to the ethical principles of the Helsinki Declaration (Ethical Principles for Medical Research Involving Human Subjects), and no ethical concerns were raised by the ethics committee of the medical faculty of the Goethe University Frankfurt, Germany.

\section{Consent for publication}

Not Applicable.

\section{Competing interests}

$C L, W W, V B, J S$ and TS declare, that they have nothing to disclosure. WB reports Consulting fees from Novartis, Payment or honoraria for lectures, presentations, speakers bureaus, manuscript writing or educational events from Astellas, Charité, Chiesi, Deutscher Ärzteverlag, Else-Kröner-Stiftung, European Society of Organ Transplantation (ESOT), Falk Foundation, Gesundheit Österreich GmbH, GORE Deutschland, Medac GmbH, MCI Academy, Novartis, Sanofi, Sanofi-Genzyme and Sirtex. He reports support for attending meetings and/or travel from Astellas, Aye Congresse GmbH, Charité, Chiesi, Deutscher Ärzteverlag, Deutscher Krebskongress, GORE Deutschland, Hopscotch Paris, 
Interplan, MCE, Medupdate GmbH, Novartis and Springer Verlag, Participation on a Data Safety Monitoring Board or Advisory Board from Novartis, and Leadership or fiduciary role in other board, society, committee or advocacy group, unpaid as Past President, Deutsche Gesellschaft für Allgemein und Viszeralchirurgie (DGAV).

\section{Author details}

${ }^{1}$ Goethe-University Frankfurt/Main, Department of General, Visceral, Transplantation and Thoracic Surgery, Goethe-University Frankfurt am Main, Frankfurt University Hospital and Clinics, Theodor-Stern-Kai 7, 60596 Frankfurt/Main, Germany. ${ }^{2}$ Department of Oral Surgery and Implantology, Goethe-University Frankfurt am Main, Carolinum, Theodor-Stern-Kai 7, 60596 Frankfurt/Main, Germany. ${ }^{3}$ Goethe-University Frankfurt am Main, Frankfurt interdisciplinary simulation center FIneST, Medical Faculty, Goethe University, Frankfurt, Germany. ${ }^{4}$ Goethe-University Frankfurt am Main, Department of Trauma, Hand and Reconstructive Surgery, University Hospital Frankfurt, Goethe-University Frankfurt am Main, Frankfurt/Main, Germany.

Received: 21 August 2021 Accepted: 14 December 2021

Published online: 03 January 2022

\section{References}

1. Rakel D, Barrett B, Zhang Z, Hoeft T, Chewning B, Marchand L, et al. Perception of empathy in the therapeutic encounter: effects on the common cold. Patient Educ Couns. 2011;85(3):390-7.

2. Nightingale SD, Yarnold PR, Greenberg MS. Sympathy, empathy, and physician resource utilization. J Gen Intern Med. 1991;6:420-3.

3. Enkling $N$, Jöhren HP, Bürklein S, Lenk M, Margraf-Stiksrud J, Beck G, Daubländer M, Wölber J, Wannemüller A, Dünniger P et al. S3-Leitlinie, Zahnbehandlungsangst beim Erwachsenen. AWMF online 2019.

4. Berggren U, Meynert G. Dental fear and avoidance: causes, symptoms, and consequences. J Am Dent Assoc. 1984;109(2):247-51.

5. Calatayud J, Calatayud F, Manso FJ, Lucas M. Anxiety and fear of dental treatment. 1. Consequences and causes. Rev Esp Estomatol. 1988;36(3):177-86.

6. Approbationsordnung für Zahnärzte und Zahnärztinnen (ZApprO). In. Edited by Gesundheit Bf; 2019.

7. Fischer MR, Bauer D, Mohn K, Projektgruppe N: Finally finished! National Competence Based Catalogues of Learning Objectives for Undergraduate Medical Education (NKLM) and Dental Education (NKLZ) ready for trial. GMS Z Med Ausbild 2015, 32(3):Doc35.

8. CanMEDS. Extract from the CanMEDS 2000 project societal needs working group report. Med Teach 2000. 2000;22(6):549-54.

9. Mayer JD, Salovey P, Caruso DR. Emotional intelligence: theory, findings, and implications. Psychol Inq. 2004;15(3):197-215.

10. O'Connor PJ, Hill A, Kaya M, Martin B. The measurement of emotional intelligence: a critical review of the literature and recommendations for researchers and practitioners. Front Psychol. 2019;10:1116.

11. Mayer JD, Salovey P, Caruso DR, Sitarenios G. Measuring emotional intelligence with the MSCEIT V2.0. Emotion. 2003;3(1):97-105.

12. Hannah A, Lim BT, Ayers KM. Emotional intelligence and clinical interview performance of dental students. J Dent Educ. 2009;73(9):1107-17.

13. MacCann C, Jiang Y, Brown LER, Double KS, Bucich M, Minbashian A Emotional intelligence predicts academic performance: a meta-analysis. Psychol Bull. 2020;146(2):150-86.

14. Davis SK, Nichols R. Does emotional intelligence have a "Dark" side? A Review of the Literature. Front Psychol. 2016;7:1316.

15. Ann BY, Yang CC. The moderating role of personality traits on emotional intelligence and conflict management styles. Psychol Rep. 2012;110(3):1021-5

16. Petrides KV, Vernon PA, Schermer JA, Veselka L. Trait emotional intelligence and the dark triad traits of personality. Twin Res Hum Genet. 2011;14(1):35-41.

17. McCrae RR, John OP. An introduction to the five-factor model and its applications. J Pers. 1992;60(2):175-215.

18. Hojat M, Gonnella JS, Nasca TJ, Mangione S, Veloksi JJ, Magee M. The Jefferson scale of physician empathy: further psychometric data and differences by gender and specialty at item level. Acad Med. 2002;77(10 Suppl):S58-60.
19. Davis MH. Measuring individual differences in empathy: evidence for a multidimensional approach. J Pers Soc Psychol. 1983;44(1):113-26.

20. Mercer SW, Maxwell M, Heaney D, Watt GC. The consultation and relational empathy (CARE) measure: development and preliminary validation and reliability of an empathy-based consultation process measure. Fam Pract. 2004;21(6):699-705.

21. Preusche I, Wagner-Menghin M. Rising to the challenge: cross-cultural adaptation and psychometric evaluation of the adapted German version of the Jefferson scale of physician empathy for students (JSPE-S). Adv Health Sci Educ Theory Pract. 2013;18(4):573-87.

22. Neumann M, Scheffer C, Tauschel D, Lutz G, Wirtz M, Edelhauser F: Physician empathy: definition, outcome-relevance and its measurement in patient care and medical education. GMS Z Med Ausbild 2012, 29(1):Doc11.

23. Rammstedt $B$, John O. Kurzversion des Big Five Inventory (BFI-K) [Short version of the big five inventory (BFI-K)]. Diagnostica. 2005;51:195-206.

24. Austin EJ. Measurement of ability emotional intelligence: results for two new tests. Br J Psychol. 2010;101(Pt 3):563-78.

25. Watanabe S, Yoshida T, Kono T, Taketa H, Shiotsu N, Shirai H, et al. Relationship of trainee dentists' self-reported empathy and communication behaviors with simulated patients' assessment in medical interviews. PLoS One. 2018;13(12):e0203970.

26. Neumann M, Edelhauser F, Tauschel D, Fischer MR, Wirtz M, Woopen C, et al. Empathy decline and its reasons: a systematic review of studies with medical students and residents. Acad Med. 2011;86(8):996-1009.

27. Chatterjee A, Ravikumar R, Singh S, Chauhan PS, Goel M. Clinical empathy in medical students in India measured using the Jefferson scale of empathy-student version. J Educ Eval Health Prof. 2017;14:33.

28. Fischer AH, Kret ME, Broekens J. Gender differences in emotion perception and self-reported emotional intelligence: a test of the emotion sensitivity hypothesis. PLoS One. 2018:13(1):e0190712.

29. Cabello R, Sorrel MA, Fernandez-Pinto I, Extremera N, Fernandez-Berrocal P. Age and gender differences in ability emotional intelligence in adults: a cross-sectional study. Dev Psychol. 2016;52(9):1486-92.

30. Walfish S, McAlister B, O'Donnell P, Lambert MJ. An investigation of self-assessment bias in mental health providers. Psychol Rep. 2012;110(2):639-44.

31. McKinley SK, Petrusa ER, Fiedeldey-Van Dijk C, Mullen JT, Smink DS, Scott-Vernaglia SE, et al. Are there gender differences in the emotional intelligence of resident physicians? J Surg Educ. 2014;71(6):e33-40.

32. Hojat M, Zuckerman M. Personality and specialty interest in medical students. Med Teach. 2008;30(4):400-6.

33. Song Y, Shi M. Associations between empathy and big five personality traits among Chinese undergraduate medical students. PLoS One. 2017;12(2):e0171665.

34. Johnson DR. Emotional intelligence as a crucial component to medical education. (2042-6372 (Electronic)).

35. Omid A, Haghani F, Adibi P. Emotional Intelligence: An Old Issue and a New Look in Clinical Teaching. (2277-9175 (Print)).

36. Austin EJ, Farrelly D, Black C, Moore H. Emotional intelligence, Machiavellianism and emotional manipulation: does El have a dark side? Pers Indiv Differ. 2007;43(1):179-89.

37. Petrides KV, Pita R, Kokkinaki F. The location of trait emotional intelligence in personality factor space. Brit J Psychol. 2007;98:273-89.

38. Brannick MT, Wahi MM, Arce M, Johnson HA, Nazian S, Goldin SB. Comparison of trait and ability measures of emotional intelligence in medical students. Med Educ. 2009;43(11):1062-8.

39. Babar MG, Hasan SS, Yong WM, Mitha S, AI-Waeli HA. Patients' perceptions of dental students' empathic, person-centered Care in a Dental School Clinic in Malaysia. J Dent Educ. 2017;81(4):404-12.

40. Hojat M, Vergare MJ, Maxwell K, Brainard G, Herrine SK, Isenberg GA, et al. The devil is in the third year: a longitudinal study of erosion of empathy in medical school. Acad Med. 2009;84(9):1182-91.

41. Costa-Drolon E, Verneuil L, Manolios E, Revah-Levy A, Sibeoni J. Medical students' perspectives on empathy: a systematic review and metasynthesis. Acad Med. 2021;96(1):142-54.

42. Thomas MR, Dyrbye LN, Huntington JL, Lawson KL, Novotny PJ, Sloan JA, et al. How do distress and well-being relate to medical student empathy? A multicenter study. J Gen Intern Med. 2007;22(2):177-83. 
43. Brazeau CM, Schroeder R, Rovi S, Boyd L. Relationships between medical student burnout, empathy, and professionalism climate. Acad Med. 2010;85(10 Suppl):S33-6.

44. Bastian VA, Burns NR, NettelbeckT. Emotional intelligence predicts life skills, but not as well as personality and cognitive abilities. Pers Indiv Differ. 2005;39(6):1135-45.

45. Ameh PO, Uti OG, Daramola OO. Empathy among dental students in a Nigerian institution. Eur J Dent Educ. 2019;23(2):135-42.

46. Kataoka H, Iwase T, Ogawa H, Mahmood S, Sato M, DeSantis J, et al. Can communication skills training improve empathy? A six-year longitudinal study of medical students in Japan. Med Teach. 2019;41(2):195-200.

47. Daryazadeh S, Adibi P, Yamani N, Mollabashi R. Impact of narrative medicine program on improving reflective capacity and empathy of medical students in Iran. J Educ Eval Health Prof. 2020;17:3.

48. Batt-Rawden SA, Chisolm MS, Anton B, Flickinger TE. Teaching empathy to medical students: an updated, systematic review. Acad Med. 2013;88(8):1171-7.

\section{Publisher's Note}

Springer Nature remains neutral with regard to jurisdictional claims in published maps and institutional affiliations.

- fast, convenient online submission

- thorough peer review by experienced researchers in your field

- rapid publication on acceptance

- support for research data, including large and complex data types

- gold Open Access which fosters wider collaboration and increased citations

- maximum visibility for your research: over 100M website views per year

At BMC, research is always in progress.

Learn more biomedcentral.com/submissions 